This is a seminal statement on the pre-eminent position held by business communication in China's largest business school-specializing in international trade-the Beijing Institute of Foreign Trade. The authors provide some historical background, review three courses in business communication in China, summarize the method of instruction, and end with concludions and opportunities for closer academic ties with China in making business communication a truly international discipline.

\title{
Business Communication in the People's Republic of China
}

Baolin Zong

Beijing Institute of Foreign Trade

H. W. Hildebrandt

University of Michigan

CLOSING AN AMERICAN UNIVERSITY for ten years would be academic suicide, mantling dreams that would destroy faculty hope, along with student candidates preparing for careers. Yet, that unhappy escapade did occur in China during the years of the Cultural Revolution (1966-1976). Some of the teachers (including one of the authors) were sent off to the country because they were intellectuals, categorized as part of an elitist group, ranked lowest on the scale as candidates for abandonment, hounded by the Gang of Four to do manual labor in the fields or factories. But determination, good Chinese sense returned and the momentum for learning was revived, albeit interrupted by a hiatus of several years.

The above over-simplified scenario is the cheerless backdrop to this essay: the rise of business communication to a preeminent position in the largest business school in China, the Beijing (or Peking) Institute of Foreign Trade. Courage, determination, and strength to succeed are malleable words, hard to infuse in a brief essay of business communication in China, yet they form an unguessed dimension of the reportorial words which follow.

This is a statement on business communication as understood in China and focuses on (1) Background; (2) Business Communication Courses; (3) Method of Instruction. 


\section{BACKGROUND}

The Beijing Institute of Foreign Trade was established in 1954. Today the 2000-student institution is the leading business school in China specializing in foreign trade under the auspices of the Ministry of Foreign Economic Relations and Trade of the People's Republic of China. There are the usual academic units, each analogous to departments in the United States.

A review of courses in that institute implies similarity to business schools in the United States, except for massive stress on foreign trade policies, comparative studies of business, and international business law. Of interest to us is the department entitled Foreign Trade English Department. Therein are about 110 instructors: retired professors, young teachers, and a large cadre of lecturers. It is this latter category who do most of the teaching. If one counts retirees, the student-teacher ratio is about $3: 1$, an unfair figure because many of the retired professors on the staff no longer profess.

Within the Foreign Trade English Department, 35-40 instructors teach business communication, or foreign trade correspondence.

All students in the school must take three courses in business communication:

\section{- Business Correspondence (or Foreign Trade Correspondence) \\ -- Foreign Trade Negotiations \\ - Correspondence in Foreign Affairs}

Even a casual reading of the three titles reflects strangely on the Western eye: the courses are not in the usual orbit of what we consider business communication. Yet, these three can possibly be subsumed under the rubric of international business communication. We shall discuss the courses in detail later.

Thus since 1954 at the college level in China, except for the hiatus noted earlier, these have been courses in business communication, more properly explained as international business communication.

Students must meet two prerequisites to enter the above courses: a command of English and a fair knowledge of foreign trade practices. While English is the majority language used in international business, it is a woeful minority language in China. 
For some time English has been taught as a second language in the Middle Schools-superseding Russian-yet Chinese have difficulty in speaking and understanding the language. Hence, in the freshman and sophomore year at the Institute, English is required. Today more attention is paid to improving the teaching of English in the Middle Schools, and, in time, the Middle School graduates will be better equipped to handle English business communication at a higher competency level.

Having a command of English is one thing; being able to use it fluently in communication with a foreign businessperson is another. People with a sound knowledge of English are lost in the business jargon of Americans: FOB, CIF, OUS, or, "The shipment should be covered for $150 \%$ of invoice value against All Risks."'

International trade is a science demanding proficiency in various fields of expertise, but the semantic wheels on which the entire process moves is business communication. Thus students must have a viable knowledge of foreign trade practices as well as English - in letters, in forms, in reports, in telexes, in cables.

A significant amount of time in international Chinese businesses is spent translating from English into Chinese and vice versa; quite a few decision makers such as managers or general managers of the import-export corporations do not know English well, or at all. Thus when a cable, letter, or telex arrives from abroad in English, someone must translate it into Chinese-for managers.

Business communication in China involves both sending and receiving messages, along with a competence to understand the business protocol of international trade.

\section{THREE BUSINESS COMMUNICATION COURSES}

One cannot disassociate the three core business communication courses from the texts used in those courses. We shall look at them individually.

\section{Business Correspondence}

The two volumes used for this course have one central purpose: to give practical experience in handling the written correspondence in international trade transactions. A glimpse at the 
table of contents of volume one entitled Business Correspondence 1 suggests pure pragmatism.

1. Layout of a Business Letter

2. Establishing Business Relations

3. Inquiry

4. Offer

5. On Foreign Trade Policy

6. Enquiry and Offer

7. Counter-offer

8. Declining a Counter-offer

9. Confirming an Order

10. Unfavourable Reply

11. Firm Offer

12. Inquiry and Non-firm Offer

13. Repeat Order

14. Proforma Invoice

15. Transferring Business Relations

16. Terms of Payment

17. L/C Amendment (Letter of Credit)

18. Urging Establishment of $\mathrm{L} / \mathrm{C}$

19. Shipping Instructions

20. Extension of L/C

21. Shipment

22. Urging Immediate Shipment

23. Requesting L/C Amendment

24. Insurance

25. Shipping Advice

26. A Claim for Shortweight

27. Settlement of a Claim

Volume two, Business Correspondence 2, is replete with examples of letters, cables, telexes used in international trade. Each section has a precise business example, a list of words, useful expressions, and notes, along with, exercises. For example:

1. Translate the following into Chinese:

-"We are anxiously desirous of receiving new designs of this article."

-"We look forward to your prompt reply ..."

2. Complete the sentences in English:

-We are desirous of (1) followed by Chinese example

(2) followed by Chinese example...

-I am venturing to (1) followed by Chinese example 
3. Use the following words and phrases in sentences of your own:

-"in view of;"

- "venture to do;"

- "accord, follow, meet with."

4. In each of the following sentences choose the appropriate word or words in the parentheses. Be prepared to justify your choice.

- "The obstacles (by, in, on, to) the way of trade with Tanzania and Zambia were removed."

- "Erl Mar's proposition of effective payment by $D / P$ for our exports (receives, meets with, obtains) the approval of our directors."

In short, the pedagogical intent of the course is to give students (1) actual examples of written communication between companies; (2) opportunities to use some of the terms from those examples in their own business writing; and (3) translations of the content from English to Chinese and Chinese to English. There is no discussion of communication theory as found in Western texts.

\section{Foreign Trade Negotiations}

In this course, content is basically similar to that of the Business Correspondence course. However, here role playing and debate positions are assumed, students playing sender and receiver roles concerning a message.

There is no public speaking as taught in the United States. Rather, oral communication approaches discussion techniques: the give and take surrounding a question or position.

Intercultural differences are discussed in the foreign trade negotiation course. With China now open to the world it is imperative to do business with differing nations, to understand the multivaried ways of doing business, to grasp different ways of life, and especially to comprehend differences in culture.

Two additional reference books, Practical Commercial English Handbook Volumes 1 and 2, are used in the Foreign Trade course. These two volumes include the content around which the oral and further written assignments are based. For example, students read articles and then discuss pro and con positions-similar to our use of a case-for class discussion. Here is a representative list of articles for class work: 
Interview with Minister Li Chiang, Economic Report, May 5, 1979

China's Trade Dynamics Develop, Eastern Horizon, October, 1978

China: An Export Strategy to Pay for Modernization, Business Week, January 15, 1979

Chinese Seem to Ease Reins on Economy, New York Times, November 7,1978

The New Economists, Newsweek, July 3, 1978

Unemployment Problem in the West, U.S. News and World Report, November 28, 1977

While the Business Correspondence course stressed the written, this class focuses on the oral: to learn English better, to prepare the written notes that follow an oral discussion, and to debate propositions extemporaneously on opposing points of view.

\section{Correspondence in Foreign Affairs}

To our knowledge no such course as the above is positioned in the United States under the rubric of business communication. In China such a course is part of the business communication curriculum, for the following reasons. Some graduates of the Institute of Foreign Trade will work either in the Commercial Offices of Chinese Embassies abroad or in the Ministry. Thus, how to conduct written and oral communication in diplomatic affairs, with diplomatic niceties, and proper protocol, emerged. The material is for persons who leave China on trade missions or for those who will hold the position of a commercial attaché.

Both written and oral communication is the medium of idea exchange in this course. It is not so specific as the two previous courses-while it is still in its infancy-but takes a broader view of international business communication.

\section{METHODOLOGY OF INSTRUCTION}

The teaching method in Chinese Business Communication is similar to the approach in the United States. If there is a motto guiding the teaching, it is "practice makes perfect." Obviously, there is much stress placed on translation exercises (both oral and written) in order to prepare the student for real situations on leaving the Institute. 
Case studies (more properly, incidents) are also used to prepare written and oral comments.

As part of the curriculum, special arrangements are made for students to visit import and export corporations, and to attend various foreign trade fairs such as the Guangzhou Trade Fair. At the fair, for example, students might serve as interpreters at business discussions. Such an exodus from the school may last two to six months, introducing the student to a practical understanding of international commerce and international business communication.

After an extended stay off campus, students return to the campus and prepare a thesis in their last semester. Topics of such papers include subjects such as English Language as a Means of Communication in International Trade, or Problems in the Export of Chinese Goods to Japan.

\section{OBSERVATIONS}

The door to business in China is now wider open than before. The country seeks outside contracts; it yearns to catch up in a business environment where written and oral communication are the media of exchange, as was this essay by a Chinese and an American. Several concluding observations are in order.

1. The Beijing Institute of Foreign Trade has a narrower purview of business communication than do scholars in the United States. For Chinese students Business Communication is primarily practicing the written and oral media protocols used in international trade. International business communication might be a more precise phrase for the Chinese courses.

2. An absence of theoretical underpinning is noticeable. The old adage of "practice precedes theory" may be operating here, but at the moment there is a prominent lack of concepts as to what occurs between sender and receiver, and the host of other problems which intervene in the communication process. Interestingly, one of the reference books does speak about seven principles of clarity: conciseness, clearness, courtesy, completeness, concreteness, consideration, and correctness, quite similar to the Seven C's in Murphy and Peck's Effective Business Communications.

3. The shadings of meaning and examples are a bit out of 
date. Students appear to be groomed in phrases outmoded and worn, often depending upon the British "style" and spellings. Examples need to be modernized.

4. Opportunities, at an early stage, are available to us in the U.S. to help those business schools in China which have business communication as a core requirement. This means sharing ideas, providing examples, clarifying intercultural differences, arranging exchange visits - all to improve relationships between our nations and to foster business communication as a truly international discipline.

\section{$T+1$}

\section{IF YOU'RE NEW TO THE TEACHING OF BUSINESS COMMUNICATION ...}

The Teaching of Business Communication contains 40 articles and course descriptions to get you started off right. $T B C$ contains material selected from The ABCA Bulletin and elsewhere, arranged under these heads: The Beginning Teacher, Course Curricula and Content, Teaching Methods and Techniques, Grading Practices and Teaching Aids.

Even if you've been teaching for 40 years, you're sure to find something of value in this 240-page accumulation of the wisdom and experience of your colleagues.

Order now from: American Business Communication Association, University of Illinois, English Building, 608 South Wright Street, Urbana, IL 61801. $\$ 5.50$ to ABCA members; $\$ 6.50$ to nonmembers, prepaid. Please enclose your check or money order to save the $\$ 2$ invoice fee. 